\title{
Nano Selenyumun Damızlık Bıldırcınlarda Verim, Yumurta ve Sperm Kalitesi ile Kuluçka Parametreleri Üzerine Etkileri
}

\author{
Ömer SEVIM ${ }^{1 *}$, Onur TATLI ${ }^{1}$, Eren KUTER ${ }^{2}$, Ehsan KARIMIYAN ${ }^{1}$, Mehmet KAYA ${ }^{3}$, Solmaz \\ KARAARSLAN ${ }^{3}$, Uğur UÇAN ${ }^{4}$, B. Hakan KÖKSAL ${ }^{1}$, Özcan CENGiZ ${ }^{1}$, Ahmet G. ÖNOL ${ }^{1}$ \\ ${ }^{1}$ Aydın Adnan Menderes Üniversitesi Veteriner Fakültesi Hayvan Besleme ve Beslenme Hastalıkları AD, Aydın, Türkiye. \\ ${ }^{2}$ Burdur Mehmet Akif Ersoy Üniversitesi Veteriner Fakültesi Hayvan Besleme ve Beslenme Hastalıkları AD, Burdur, Türkiye. \\ ${ }^{3}$ Aydın Adnan Menderes Üniversitesi Veteriner Fakültesi Zootekni AD, Aydın, Türkiye. \\ ${ }^{4}$ Aydın Adnan Menderes Üniversitesi Veteriner Fakültesi Dölerme ve Suni Tohumlama AD, Aydın, Türkiye.
}

Geliş Tarihi: 19.12.2018

Kabul Tarihi: 31.05.2019

Özet: Bu çalışma damızlık bıldırcın rasyonlarında nano selenyum (Se) kullanılmasının verim, canlı ağırlık artışı, yumurta kalite özellikleri, sperm kalitesi, kuluçka parametreleri ve karaciğer üzerine etkilerini belirlemek amacıyla yapılmıştır. Araştırmada 20 erkek ve 60 dişi olmak üzere toplam 80 adet 10 haftalık yaşta bıldırcın (Coturnix coturnix Japonica) kullanılmıştır. Hayvanlar kontrol (K - inorganik sodyum selenit) ve deneme ( $\mathrm{D}$ - nano sodyum selenit) olmak üzere iki gruba ayrılmış, her grup altında da her biri bir (1) erkek üç (3) dişi içeren 10 adet alt grup oluşturulmuştur. Nano Se kullanılması verim, canlı ağırlık ve yem tüketimi üzerine herhangi bir önemli etki oluşturmamıştır. Ancak yumurta ağırı̆̆ı $(P<0.01)$ ve sarı rengini $(P<0,05)$ azaltırken, kabuk ağırlığı $(P<0.001)$, Haugh birimi ve kabuk indeksini $(P<0.01)$ artırdığı görülmüştür. Kabuk kalınlığında ise herhangi bir önemli etki belirlenmemiştir. Nano Se kullanımı spermatozoalarda başa bağlı bozukluk oranını artırmış $(P<0.05)$ ancak diğer morfolojik parametreleri etkilememiştir. Nano Se döllülük oranı ve kuluçka randımanını önemli düzeyde $(\mathrm{P}<0.05)$ düşürmüş, diğer kuluçka parametrelerini ise etkilememiştir. Histopatolojik olarak deneme grubundaki karaciğerlerde yağ vakuolleri olduğu belirlenmiştir. Sonuç olarak, rasyonlarda $0.2 \mathrm{mg} / \mathrm{kg}$ nano Se'nin kullanılması genel olarak olumsuz bir etki oluşturmuştur. Bu nedenle daha düşük düzeylerde kullanılması önerilebilir.

Anahtar Kelimeler: Bıldırcın, Nano selenyum, Yumurta kalitesi, Sperm kalitesi, Kuluçka parametreleri.

\section{Effects of Nano Selenium on Performance, Egg Quality, Sperm Quality and Hatching Parameters of Breeding Quails}

Abstract: This study was conducted to determine the effects of using nano selenium (Se) on breeding quail rations on reproductive performance, weight gain, egg quality, sperm quality, hatching parameters and liver. A total of 80 (20 males and 60 females), 10 week old quails (Coturnix coturnix Japonica) were used in the study. The animals were divided into two groups as control ( $\mathrm{K}$ - inorganic sodium selenite) and experiment ( $\mathrm{C}$ - nano sodium selenite) with 10 replicates each having one male and three female. The use of nano Se does not have any significant effect on productive performance, weight gain and feed consumption. However, it decreased the egg weight $(P<0.01)$ and the yellow color $(P<0.05)$ and, increased the shell weight $(P<0.001)$, Haugh unit and shell index $(P<0.01)$. No significant effect was determined in the shell thickness. Nano Se increased head defects $(P<0.05)$ in spermatozoa but did not affect other morphological parameters. Nano Se decreased the fertility and hatchability of total eggs $(P<0.05)$, while other hatching parameters were not affected. Histopathologically the hepatic changes in experiment group were characterized by fat vacuoles. As a result, the use of 0.2 $\mathrm{mg} / \mathrm{kg}$ nano Se in breeding quail rations generally has a negative effect. For this reason nano Se may be recommended to use at lower levels.

Keywords: Quail, Nano selenium, Egg quality, Sperm quality, Hhatching parameters.

\section{Giriş}

Selenyum (Se) yaşamın sürdürülebilmesi, büyüme, bağışıklık ve üreme gibi fizyolojik fonksiyonlar ile antioksidan aktivite için gerekli olan esansiyel bir elementtir. Vücut içerisinde Se, selenoproteinlerin bir parçası olarak selosistin formunda bulunur (Surai ve Fisinin, 2014).

Rasyonlarda kullanılan selenyumun inorganik ve organik olmak üzere temel iki formu vardır. Bitkilerdeki Se sadece organik formda ve başlıca selenometiyonindir (Surai, 2002). Sodyum selenit ve sodyum selenat ise inorganik Se kaynakları olarak kanatlı rasyonlarına katılabilmektedir (Hasan, 2011).
Özellikle son yıllarda ilgi gösterilen bir diğer Se formu da nano Se dur (Swain ve ark., 2015). Nano teknoloji, mühendislik, sağlık, gıda, ilaç ve bilgi teknolojileri gibi birçok alanda kullanılmakta olup, son yıllarda tarım ve hayvancılık alanlarında da kullanılmaya başlanılmıştır. Nano teknoloji, herhangi bir maddenin nano boyutlara (1-100 nm) indirilmesi ve bu şekilde kullanılmasıdır (Swain ve ark., 2015). Nano teknoloji ile üretilen yem katkı maddeleri daha geniş yüzey alanına sahip olduğu için diğer formlara göre sindirim sisteminden daha kolay ve etkili emilir (Uniyal ve ark., 2017). 
Yapılan literatür taramaları sonucunda bıldırcın rasyonlarında nano Se kullanımının yumurta verimi (Pratheebha ve ark., 2018), çıkım oranı (Pratheebha ve Revathi, 2018a) ve kuluçka randımanı (Pratheebha ve Revathi, 2018b) üzerine etkilerine yönelik çalışmalar yapılmış olsa da yeterli sayıda olmadığı görülmüştür. Ayrıca nano selenyumun bıldırcınlarda yumurta kalite özellikleri, sperm kalitesi ve karaciğer üzerine etkilerini irdeleyen herhangi bir çalışmaya rastlanmamıştır. Bu amaç doğrultusunda, söz konusu çalışma ile nano selenyumun damızlık bıldırcın rasyonlarında kullanılmasının verim, yumurta kalite özellikleri, sperm kalitesi, kuluçka parametreleri ve karaciğer üzerine etkileri incelenmiştir.

\section{Materyal ve Metot}

Araştırma Adnan Menderes Üniversitesi Veteriner Fakültesi Kanatlı Araştırma Birimi'nde, ADÜ HADYEK (Aydın Adnan Menderes Üniversitesi Hayvan Deneyleri Yerel Etik Kurulu) tarafından verilen 64583101/2018/113 sayılı izin ile yürütülmüştür. Denemede 20 erkek ve 60 dişi olmak üzere toplam 80 adet 10 haftalık yaşta bıldırcın (Coturnix coturnix Japonica) kullanılmıştır. Hayvanlar canlı ağırlıkları birbirine yakın olacak biçimde kontrol ( $K$ - inorganik sodyum selenit) ve deneme ( $D$ - nano sodyum selenit) olmak üzere iki gruba ayrılmış, her grup altında da her biri bir (1) erkek üç (3) dişi içeren 10 adet alt grup oluşturulmuştur. Deneme rasyonları NRC (National Research Council) (1994)'ye göre hazırlanmıştır (Tablo 1).

\begin{tabular}{llll}
\multicolumn{3}{l}{ Tablo 1. Rasyon bileşimi ve hesapla bulunan besin madde değerleri. } \\
\hline \multicolumn{3}{l}{ Yem hammaddeleri, \% } & Hesapla bulunan değerler \\
\hline Mısır & 58.35 & ME, kcal/kg & 29.06 \\
Soya fasulyesi küspesi, \%48 & 31 & Ham protein, \% & 20.1 \\
Ayçiçeği yağı & 2 & Ham selüloz, \% & 2.5 \\
Kireç taşı & 6.6 & Ham yă̆, \% & 3.75 \\
Dikalsiyum fosfat & 1.3 & Kalsiyum, \% & 2.52 \\
Tuz & 0.4 & Yararlanılabilir fosfor, \% & 0.35 \\
Vit.-min. karması* & 0.25 & Lizin, \% & 1.07 \\
DL-metiyonin & 0.1 & Metiyonin+sistin, \% & 0.74 \\
& & Selenyum**, mg/kg & 0.25 \\
\hline
\end{tabular}

* Her 2,5 kilogram vitamin-mineral karmasında A vitamini $12000000 \mathrm{IU}, \mathrm{D}_{3}$ vitamin $2400000 \mathrm{IU}$, E vitamini $20000 \mathrm{mg}, \mathrm{K}_{3}$ vitamini $4000 \mathrm{mg}, \mathrm{B}_{1}$ vitamini $3000 \mathrm{mg}$,

$B_{2}$ vitamini $7000 \mathrm{mg}$, niasin $25000 \mathrm{mg}$, kalsiyum D pantotenat $10000 \mathrm{mg}, B_{6}$ vitamini $5000 \mathrm{mg}, B_{12}$ vitamini $15 \mathrm{mg}$, D biotin $75 \mathrm{mg}$, folik asit $1000 \mathrm{mg}$, kolin klorid $125000 \mathrm{mg}$, manganez $100000 \mathrm{mg}$, demir $60000 \mathrm{mg}$, çinko $60000 \mathrm{mg}$, bakır 5000 $\mathrm{mg}$, kobalt $200 \mathrm{mg}$, iyot $1000 \mathrm{mg}$ bulunmaktadır.

** Rasyonlara inorganik ve nano sodyum selenit $0.2 \mathrm{mg} / \mathrm{kg}$ Se sağlayacak şekilde **Rasyonlara inorganik ve nano sodyum selenit $0.2 \mathrm{mg} / \mathrm{kg}$ Se sağlayacak şekide
katılış̧ır. Bu amaçla, \%10 saflıktaki inorganik sodyum selenitten $4.44 \mathrm{mg} / \mathrm{kg} \% 99.9$ saflıktaki nano sodyum selenitten $0.44 \mathrm{mg} / \mathrm{kg}$ kullanılmışıtır.

Her alt grup $32 \times 28 \times 20 \mathrm{~cm}$ boyutlarındaki kafes bölmelerinde barındırılmış, yem ve su ad libitum olarak sunulmuştur. Sıcaklık ve nem değerleri günlük olarak ölçülmüştür (ortalama $25{ }^{\circ} \mathrm{C}$ sıcaklık ve $\% 50$ nem). Deneme boyunca 16 saat aydınlık 8 saat karanlık uygulanmıştır. Gruplardaki yumurta veriminin benzerliğini kontrol etmek ve adaptasyonu sağlamak amacıyla iki hafta alıştırma periyodu uygulanmış ardından denemeye başlanarak 10 hafta sürdürülmüştür. Nano Se Cumhuriyet Üniversitesi Nanoteknoloji Mühendisliği Laboratuvarında üretilmiştir.

Araştırmanın başında ve sonunda bütün hayvanlar tartılarak canlı ağırlıkları belirlenmiştir. Yumurta verimleri günlük, yumurta ağırlıkları ve yem tüketimleri ise iki haftada bir tespit edilmiştir. íki haftada bir, her alt gruptan elde edilen yumurtaların tamamında yumurta kalite özellikleri incelenmiştir. Öncelikle yumurtalar tartılarak ağırlıkları tespit edilmiş ve ardından düz bir zemin üzerine kırılarak ak ve sarı yükseklikleri $0.01 \mathrm{~mm}$ hassasiyetindeki mikrometre ile çapları ise dijital kumpas yardımıyla ölçülmüştür. Sarı rengi DSM Roche yumurta sarısı renk katalogu ile belirlenmiştir. Yumurta kabukları dikkatlice yıkanarak zarlardan temizlenmiş, 24 saat $40{ }^{\circ} \mathrm{C}^{\prime}$ de kurutulmuş ve ardından $0.1 \mathrm{~g}$ hassas terazide tartılmıştır. Kabuk kalınlıkları üç farklı yerden (sivri ve küt uç ile yan bölge) ölçülüp bu ölçümlerin aritmetik ortalaması alınmıştır. Haugh birimi Haugh (1937), kabuk indeksi ise Sauveur'e (1988) göre hesaplanmıştır.

Denemenin son bir haftasında elde edilen yumurtalar $12^{\circ} \mathrm{C}$ sıcaklık ve $\% 80$ nem düzeyinde depolanmış ve bu yumurtalardan 120 tanesi kuluçka parametrelerini (döllülük oranı, kuluçka randımanı çıkım gücü, erken ve geç embriyonik ölüm ile çıkım ağırlığı) incelemek üzere kuluçka makinesine $\left(37.5^{\circ} \mathrm{C}\right.$ ve $\% 55-60$ nem) yerleştirilmiştir.

Denemenin bitirilmesinden sonraki bir hafta boyunca erkekler dişilerden ayrılarak bireysel kafeslere alınmış ve deneme rasyonlarını tüketmeye devam etmişlerdir. Bu süre zarfında erkeklerden sperm alınarak morfolojik bozukluklar incelenmiştir. Alınan spermler Hancock solüsyonu içerisine konularak faz kontrast mikroskopta normal ve anormal (baş, orta ve kuyruk bozuklukları) spermatozoa düzeyleri belirlenmiştir.

Deneme sonunda kontrol ve deneme gruplarından beşer hayvan kesilerek karaciğerleri alınmış ve \%10 formalin solüsyonunda oda sıcaklı̆̆ında fikse edilmiştir. Parafin bloklama ardından hematoksilen eozin boyama yapılarak ışık mikroskop altında incelenmiştir (Bancroft ve ark., 1996).

Deneme sonunda elde edilen verilerin analizlerinde SPSS 22.0 programı kullanılmıştır. Canlı ağırlık, yem tüketimi, kabuk kalınlığı ve çıkım ağırlığı için t testi, yumurta verim oranı, döllülük oranı, kuluçka randımanı, çıkım oranı, erken ve geç embriyonik ölüm oranı için iki yüzde arası önemlilik testi, yumurta ağırlığı, kabuk ağırlığı, sarı rengi, Haugh birimi, kabuk indeksi ve spermatozoalardaki morfolojik bozukluk verileri için Mann-Whitney U testi yapılmıştır (SPSS, 2013). 


\section{Bulgular}

Deneme süresince ölüm görülmemiştir. Araştırmada canlı ağırlık ve yumurta verimlerine ilişkin parametreler Tablo 2'de sunulmuştur. Bıldırcın rasyonlarında nano Se kullanılmasının verim, canlı ağırlık ve yem tüketimi üzerine istatistiksel açıdan herhangi bir etkiye sahip olmadığı görülmüştür.

Tablo 2. Nano selenyumun verim ve canlı ağırlık üzerine etkileri (ortalama $\pm \mathrm{SH}$ ).

\begin{tabular}{llll}
\hline Parametre & Kontrol & Deneme & $\mathbf{P}$ \\
\hline Başlangı̧ canlı ağırık, g & $249.50 \pm 4.56$ & $244.55 \pm 5.24$ & ÖD \\
Bitiş canlı ağırlık, g & $255.21 \pm 6.06$ & $244.41 \pm 5.60$ & ÖD \\
Yem tüketimi, g/gün/hayvan & $26.77 \pm 0.81$ & $27.44 \pm 0.57$ & ÖD \\
Yumurta verim oranı, \% & $83.61 \pm 1.05$ & $80.67 \pm 1.64$ & ÖD \\
\hline
\end{tabular}

Yumurta kalite özelliklerine yönelik olarak nano selenyumun kabuk kalınlığı dışındaki incelenen bütün parametreleri istatistiksel olarak önemli düzeyde etkilediği belirlenmiştir (Tablo 3). Nano Se kullanımı ile yumurta ağırlığı $(P<0.01)$ ve sarı rengi $(P<0.05)$ azalırken kabuk ağırlığı $(P<0.001)$, Haugh birimi ve kabuk indeksi $(P<0.01)$ artmıştır.

Tablo 3. Nano selenyumun yumurta kalite özellikleri üzerine etkileri (ortalama $\pm \mathrm{SH}$ ).

\begin{tabular}{llll}
\hline Parametre & Kontrol & Deneme & $\mathbf{P}$ \\
\hline Yumurta ağırlığı, g & $12.49 \pm 0.12$ & $11.89 \pm 0.11$ & $* *$ \\
Kabuk ağırlığı, g & $0.98 \pm 0.01$ & $0.99 \pm 0.74$ & $* * *$ \\
Kabuk kalınlığı, mm & $0.22 \pm 0.002$ & $0.22 \pm 0.002$ & ÖD \\
Sarı rengi & $3.32 \pm 0.09$ & $3.00 \pm 0.11$ & $*$ \\
Haugh birimi & $86.39 \pm 0.31$ & $87.47 \pm 0.48$ & $* *$ \\
Kabuk indeksi, g/100 $\mathrm{cm}^{2}$ & $3.90 \pm 0.33$ & $4.02 \pm 0.29$ & $* *$ \\
\hline SH: Standart hata, ÖD: Önemli değil, *: P<0.05, **:P<0.01, ***:P<0.001 &
\end{tabular}

Tablo 4'de nano Se kullanımının spermatozoalardaki morfolojik bozukluklar ve bunların bölgesel dağılımı üzerine elde edilen bulgular sunulmuştur. Buna göre deneme grubunda morfolojik bozukluğu olan spermatozoa oranın daha fazla olduğu, kontrol grubundaki bozuklukların çoğunlukla kuyruğa bağlı olduğu (\%19.2), deneme grubunda ise başa bağlı olduğu (\%19.2) görülmüştür. Gruplar arası farkın başa bağlı bozukluk oranlarında istatistiksel olarak önemli $(P<0.05)$, diğer parametreler açısından önemsiz olduğu tespit edilmiştir.

Tablo 4. Nano selenyumun spermatozoalardaki morfolojik bozukluklar üzerine etkisi (\%) (ortalama \pm SH).

\begin{tabular}{llll}
\hline Morfolojik bozukluk & Kontrol & Deneme & $\mathbf{P}$ \\
\hline Başa bağıı & $7.6 \pm 1.99$ & $19.2 \pm 3.43$ & $*$ \\
Orta kısma bağlı & $5.4 \pm 1.29$ & $3.6 \pm 1.47$ & ÖD \\
Kuyruğa bağlı & $19.2 \pm 4.07$ & $14.6 \pm 4.38$ & ÖD \\
Toplam & $32.2 \pm 2.58$ & $37.4 \pm 3.59$ & ÖD \\
\hline
\end{tabular}

SH: Standart hata, ÖD: Önemli değil, *: P<0.05
Denemenin kuluçka parametrelerine ilişkin bulgular Tablo 5'de sunulmuştur. Nano Se kullanılan grupta döllülük oranı ve kuluçka randımanının istatistiksel olarak önemli düzeyde $(P<0.05)$ düştüğü tespit edilmiştir. Erken embriyonik ölüm ve çıkım oranları nano Se kullanımından olumsuz etkilenmesine rağmen bu durumun istatistiksel olarak önemli olmadığı belirlenmiştir.

Tablo 5. Nano selenyumun kuluçka parametreleri üzerine etkileri (ortalama $\pm \mathrm{SH}$ ).

\begin{tabular}{llll}
\hline Parametre & Kontrol & Deneme & P \\
\hline Döllülük oranı, \% & 92.92 & 84.40 & $*$ \\
Kuluçka randımanı, \% & 84.07 & 69.72 & $*$ \\
Çıkım oranı, \% & 90.48 & 82.61 & ÖD \\
Erken embriyonik ölüm oranı, \% & 0.95 & 5.43 & ÖD \\
Geç embriyonik ölüm oranı, \% & 8.57 & 11.95 & ÖD \\
Çıkım ağırlı̆̆ı, g/hayvan & $9.16 \pm 0.83$ & $9.00 \pm 0.10$ & ÖD \\
\hline SH: Standart hata, ÖD: Önemli değil, *: P<0.05 & &
\end{tabular}

Yapılan karaciğer incelemesinde makroskobik olarak herhangi bir değişiklik görülmese de mikroskobik olarak deneme grubundaki hayvanlarda yağ vakuolleri saptanmıştır (Şekil 1).
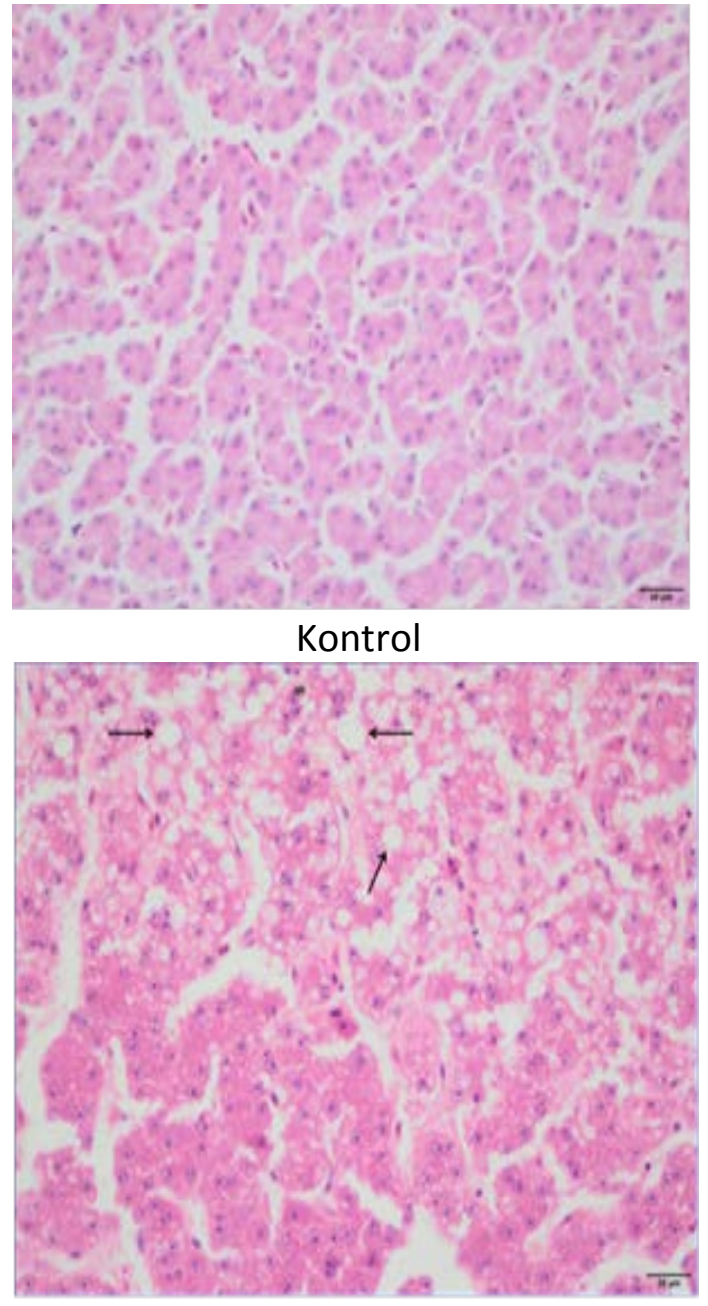

Deneme

Şekil 1. Karaciğerlerin mikroskobik görüntüsü (40x, HxE). 


\section{Tartışma ve Sonuç}

Verim ve canlı ağırlık parametreleri üzerine gruplar arasında herhangi bir istatistiksel önem görülmemiştir. Bulgularımıza benzer biçimde Eldin ve ark. (2015) yumurtacı tavuk rasyonlarında inorganik veya organik yerine nano selenyum kullanılmasının $(0.3 \mathrm{mg} / \mathrm{kg})$ verim, yem tüketimi ve canlı ağırlık üzerine herhangi bir önemli etkisi olmadığını bildirmiştir.

Nano selenyumun yumurta kalite özelliklerine yönelik etkileri Tablo 3'de sunulmuştur. Yumurtacı hindilerde yapılan bir çalışma sonucunda organik Se kullanılan grupta inorganik kullanılan gruba (her iki grupta $0.3 \mathrm{mg} / \mathrm{kg})$ göre daha düşük $(P<0.05)$ yumurta ağırıkları elde edilirken nano form $(0.15$ $\mathrm{mg} / \mathrm{kg}$ ) kullanılan grup ile diğer gruplar arasında önemli fark olmadığı belirlenmiştir (İsmail ve ark., 2016). Baylan ve ark. (2011) tarafından Japon bıldırcınlarında selenyumun form (inorganik ve organik) ve miktarının $(0.1,0.2$ ve $0.3 \mathrm{mg} / \mathrm{kg}$ ) yumurta kalitesine etkilerinin incelendiği araştırma sonucunda hem organik form kullanılmasının hem de miktar artışının kabuk ağırlığını, Haugh birimini ve kabuk kalınlığını artırdığı $(P<0.05)$ bildirilmiştir. Yapılan bir diğer çalışmada selenyumun form (inorganik ve organik) ve miktarının ( 0.15 ve 0.30 $\mathrm{mg} / \mathrm{kg}$ ) yumurtacı tavuklarda yumurta kalitesine etkileri incelenmiş, hem Se formunun hem de kullanım miktarının Haugh birimi ve kabuk kalınlığını etkilemediği tespit edilmiştir (Radwan ve ark., 2015). Yapılan çalışmaların birçoğunda Se form ve miktarının yumurta sarı rengini değiştirmediği bildirilmiştir (İsmail ve ark., 2016; Radwan ve ark., 2015). Ancak Zdunczyk ve ark., (2013) yumurtacı tavuk rasyonlarında selenyum miktarının $0.15^{\prime}$ den $0.30 \mathrm{mg} / \mathrm{kg}^{\prime}$ a çıkarılması ile sarı renginin düştüğünü $(P<0.05)$ saptamışlardır. Skrivan ve ark., (2013) yumurtacı tavuk rasyonlarında inorganik veya organik selenyum kullanılmasının kabuk indeksine etkisinin olmadığını bildirmiştir.

Nano formun hem yüzey alanının hem de biyoyararlanımının inorganik ve organik formlara göre çok daha yüksek olması nedeniyle metabolizmadaki etkinliği daha fazla olmakta ve hatta toksik etki yaratabilmektedir. Yumurta kalite özelliklerine ilişkin gruplar arası değişimler bu sebeple ortaya çıkmış olabilir. Ayrıca deneme grubundaki karaciğer yağlanması da (Şekil 1) bu durumu destekler niteliktedir. Radwan ve ark. (2015) tarafından yumurtacı tavuklar üzerinde yapılan bir çalışmada hem Se formu (inorganik ve nano) hem de rasyondaki düzeyinin $(0.10,0.25$ ve $0.40 \mathrm{mg} / \mathrm{kg}$ ) karaciğer üzerine etkileri incelenmiştir. Deneme sonuçlarına göre rasyonda hem nano Se kullanılmasının hem de Se düzeyindeki artışın karaciğerde yağlanmaya ve yağ vakuolleri oluşumuna neden olduğu bildirmiştir.

Spermatozoalardaki morfolojik bozukluk oranları incelendiğinde kontrol ve deneme grubunda nano selenyum kullanılmasının başa bağlı bozuklukları artırdığı $(\mathrm{P}<0.05)$ diğer parametreleri ise etkilemediği tespit edilmiştir (Tablo 4). Hasan (2011) bıldırcın rasyonlarındaki organik Se oranının $2.5 \mathrm{mg} / \mathrm{kg}^{\prime} ı$ üzerine çıktığında sperm kalitesini (motilite, normal spermatozoa oranı ve konsantrasyon) olumsuz etkilediğini $\quad(P<0.05)$ bildirmiştir. Deneme grubunda görülen olumsuz etki, nano formun etkinliğinin daha fazla olmasına bağlanabilir.

Tablo 5'de nano selenyumun kuluçka parametrelerine etkisi sunulmuştur. Buna göre bütün parametreler nano Se kullanımından olumsuz etkilenirken döllülük oranı ve kuluçka randımanındaki değişimler önemli $\quad(P<0.05)$ bulunmuştur. Hasan (2011) rasyondaki organik Se oranı $2.5 \mathrm{mg} / \mathrm{kg}^{\prime} ı$ üzerine çıktığında döllülük oranının düştüğünü $(P<0.05)$, Attia ve ark. (2010) ise inorganik yerine organik Se kullanılmasının kuluçka randımanını $(P<0.05)$ ve döllülük oranını düşürdüğünü, embriyonik ölüm oranını ise artırdığını bildirmiştir. Yapılan bir diğer çalışmada ise Se formunun (inorganik, organik ve nano) hindilerde kuluçka randımanı ve çıkım oranı üzerine önemli etkilerinin olmadığı tespit edilmiştir (İsmail ve ark., 2016). Nano Se kullanımı ile döllülük oranı ve kuluçka randımanında oluşan olumsuz etki, spermatozoalardaki başa bağlı bozuklukların artmasına bağlanabilir.

Karaciğer incelemesi sonucunda kontrol grubunda herhangi bir değişim görülmezken deneme grubunda yağlanma ve yağ vakuolleri belirlenmiştir. Benzer şekilde Radwan ve ark. (2015) hem nano Se kullanılması hem de rasyondaki Se düzeyinin artışı $(0.40 \mathrm{mg} / \mathrm{kg})$ ile yumurtacı tavuklarda karaciğerde yağlanma ve yağ vakuolleri oluştuğunu bildirmiştir. Bu durum da yine nano formun etkinliğinin diğer formlara göre daha fazla olmasına bağlanabilir.

Sonuç olarak damızlık bıldırcın rasyonlarında NRC (1994)'nin tavsiye ettiği düzeyde $(0.2 \mathrm{mg} / \mathrm{kg})$ selenyumu karşılamak için nano formun kullanılmasının her ne kadar verim ve canlı ağırlık üzerine etkisinin olmadığı belirlense de yumurta ağırlığı, sarı rengi, döllülük oranı, kuluçka randımanı ve karaciğer üzerine olumsuz etkilerinin olduğu görülmüştür. Bu verilere dayanarak nano formun inorganik ve organik formlara göre daha toksik olduğu, bu nedenle damızlık bıldırcın rasyonları için $0.2 \mathrm{mg} / \mathrm{kg}$ nano Se düzeyinin fazla olduğu ve daha düşük miktarda kullanılması gerektiği söylenebilir. 
Bu amaçla damızlık bıldırcın rasyonlarında en uygun nano Se düzeyinin belirlenmesine yönelik daha fazla araştırma yapılmasının gerekli olduğu görülmüştür.

\section{Kaynaklar}

Attia YA, Abdalah AA, Zeweil HS, Bovera F, Tag El-Din AA, Araft MA, 2010: Effect of inorganic or organic selenium supplementation on productive performance egg quality and some physiological traits of dual-purpose breeding hens. Czech Anim Sci, 11, 505-519.

Bancroft JD, Stevens A, Turner DR, 1996: Theory and Practice of Histological Techniques. London, Churchill Livingstone.

Baylan M, Canoğulları S, Ayasan T, Copur G, 2011: Effects of dietary selenium source storeage time and temperature on the quality of quail eggs. Biol Trace Elem Res, 143, 957-964.

Eldin TAS, Hamady GAAH, Abdel-Moneim MA, Farroh KY, El-Reffaei WHM, 2015: Nuritional evaluation of selenium-methionine nanocomposite as a novel dietary supplement for laying hens. Journal of Anim Health and Prod, 3 (3), 64-72.

Hasan M, 2011: Effect of organic selenium supplementation on male quail reproduction. MSc Thesis. Department of Poultry Science, Bangladesh Agricultural University, Mymensingh.

Haugh RR, 1937: The Haugh unit for measuring egg quality. US Poult Mag, 43, 552-573.

İsmail FSA, Mostafa MY, Azzam MMM, Gorgy MAL, 2016: Effect of some sources of antioxidants on the productive and reproductive performance of turkey hens. J Anim and Poultry Prod,7 (10), 393-401.

NRC (National Research Council), 1994: Nutrient Requirements of Ring-Necked Pheasants, Japanese Quail and Bobwhite Quail. Ninth Revised Ed. National Academy Press, Washington, USA.

Pratheebha Y, Revathi K, Babu M, 2018: Dietary nanoselenium increases egg production in Japanese quails (Coturnix coturnix Japonica). The Indian Veterinary Journal, 95 (5), 73-75.

Pratheebha Y, Revathi K, 2018a: Effect of nano-selenium on fertility of Japanese quail, Coturnix coturnix Japonica. J Appl Zool Res, 29 (1), 100-103.
Pratheebha Y, Revathi K, 2018b: Effect of nano-selenium on hatchability of Japanese quail, Coturnix coturnix Japonica. J Appl Zool Res, 29 (1), 104-107.

Radwan NL, Eldin TAS, El-Zaiat AA, Mostafa MASA, 2015: Effect of dietary nano-selenium supplementation on seleneium contentand oxidative stability in table eggs and productive performance of laying hens. Int J Poult Sci, 14 (3), 161-176.

Sauveur B, 1988: Reproduction des Volailles et Production d'Oeufs. INRA ed., Paris, France.

Skrivan M, Marounek M, Englmaierova M, Skrivanova V, 2013: Influence of dietary vitamin $C$ and selenium, alone and in combination on the performance of laying hens and quality of eggs. Czech Anim Sci, 2, 91-97.

SPSS, 2013: IBM SPSS Statistics Version 22.0, SPSS Inc., Mihigan Ave.,Illinois, USA., Chicago.

Surai PF, 2002: Selenium in poultry nutrition 1. Antioxidant properties, deficiency and toxicity. World's Poultry Science Journal, 58, 333-347.

Surai PF, Fisinin VI, 2014: Selenium in poultry breeder nutrition: An update. Anim Feed Sci Technol, 191, 115.

Swain PS, Rajendran D, Rao SBN, Dominic G, 2015: Preparation and effects of nano mineral particle feeding in livestock: A review. Veterinary World, 8 (7), 888-891.

Uniyal S, Dutta N, Raza M, Jaiswal SK, Sahoo JK, Ashwin K, 2017: Application of nano minerals in the field of animal nutrition: A review. Bulletin of Environment Pharmacology and Life Sciences, 6 (4), 4-8.

Zdunczyk Z, Drazbo A, Jankowski J, Juskiewicz J, Antoszkiewicz Z, Troszynska A, 2013: The effect of dietary vitamin $E$ and selenium supplements on the fatty acid profile and quality traits of eggs. Archiv Tierzucht, 72, 719-732.

*Yazışma adresi: Ömer SEVIM

Aydın Adnan Menderes Üniversitesi Veteriner Fakültesi B Blok Hayvan Besleme ve Beslenme Hastalıkları Anabilim Dalı, Işıklı Mah., Efeler, Aydın, Türkiye.

e-mail: osevim@adu.edu.tr 